\title{
REPRESENTAÇÕES, ABORDAGEM INTERCULTURAL E PEDAGOGIA TRANSLÍNGUE NO ENSINO FUNDAMENTAL I
}

\author{
Representations, Intercultural Approach and Translingual Pedagogy in \\ Fundamental Education I
}

Laura Janaina Dias AMATO

Universidade Federal da Integração Latino-Americana

laura.amato@unila.edu.br https://orcid.org/0000-0003-0339-1185

\begin{abstract}
RESUMO: O presente trabalho, fruto de um projeto de extensão implementado na rede municipal de Foz do Iguaçu, busca explorar a função das representações imagéticas no ensino com a língua adicional, a partir de uma perspectiva intercultural, com base em uma pedagogia translíngue. Neste sentido, apresentaremos a comunidade a qual o projeto foi submetido, assim como a metodologia de aplicação da ação, que, através de imagens associou objeto, língua materna e língua adicional. Contando com uma abordagem intercultural (GUILHERME; DIETZ, 2014) e apoiado em práticas translíngues (YIP; GARCÍA, 2018), pretendemos discutir como as representações multimodais auxiliam na sensibilização linguística e intercultural, aproximando sujeito e língua, através de expressões outras, apoiadas ou não pela mediação escrita. PALAVRAS-CHAVE: Pedagogia translíngue; Ensino fundamental I; Interculturalidade.
\end{abstract}

ABSTRACT: This paper, which is the result of an extension project in municipal schools in Foz do Iguaçu, seeks to explore the role of image representations in teaching with the additional language, from an intercultural perspective, based on translilingual pedagogy. In this sense, we will present the community to which the project was submitted, as well as its methodology which used images to relate object, mother tongue and additional languages. Based on an intercultural approach (GUILHERME; DIETZ, 2014) and supported by translational practices (YIP; GARCÍA, 2018), we aim to discuss how multimodal representations assist in linguistic and intercultural awareness, bringing subject and language closer together, through other expressions, supported or not by written mediation. KEYWORDS: Translingual pedagogy; Fundamental education I; Interculturality. 


\section{CONTEXTO}

O ensino de línguas adicionais para crianças não é nada recente, porém, no Brasil, durante muitos anos a língua ensinada era majoritariamente a língua inglesa (TONELLI; CHAGURI, 2013). Contudo, com a primeira versão da LDB de 1996 houve um aumento da oferta de outras línguas, priorizando o desejo de várias comunidades e valorizando as línguas de migração, e com isso a identidade linguístico-cultural do falante. Já com a lei $\mathrm{n}^{\circ} 11.161$ de 2005, a oferta de língua espanhola teve um grande avanço, tanto na rede pública, quanto na rede privada. No entanto, a revogação da lei em 2017 e a indicação na Base Nacional Comum Curricular da obrigatoriedade de oferta da língua inglesa, voltamos ao patamar anterior a LDB de 1996 e a oferta plurilíngue nas escolas diminui muito; mantendo somente de caráter opcional o ensino de uma segunda língua e colocando como primeira opção de segunda língua o espanhol, durante o Ensino Médio.

Este mesmo panorama de inclusão e exclusão de uma língua adicional no currículo pôde ser observado também nas escolas da rede municipal de Foz do Iguaçu, quando a partir da lei $\mathrm{n}^{\circ} 2.864$, de 16 de dezembro de 2003 houve a oferta da língua espanhola em toda a rede municipal, respeitando a comunidade local, pois é a segunda língua mais falada na região, logo após o português, e ampliando o escopo da lei n ${ }^{\circ} 11.161 / 05$. Porém, a oferta na rede municipal, apesar de seus percalços e de seu sucesso, não teve continuidade, sendo as aulas substituídas por outras atividades, por razões não claras à comunidade, advindas de decisões políticas. Desta forma, as crianças não têm, atualmente, a oportunidade de ter acesso a uma segunda língua durante a primeira etapa da escolarização, apesar de dados confirmarem a grande presença de crianças falantes de língua espanhola matriculadas no município (RIBEIRO, 2018).

Além do acima exposto, cabe informar que Foz do Iguaçu, assim como outras cidades de fronteira, integrou o Programa Escolas Interculturais de Fronteira (PEIF) do Ministério da Educação, advindo de um acordo firmado no Setor Educacional do MERCOSUL. A cidade participou do programa desde 2005, com uma escola situada na região próxima à fronteira argentina. Salientamos que não discutiremos aqui aspectos específicos deste programa, pois já há vasta literatura sobre o mesmo (ALVES e ALBUQUERQUE, 2019; AMATO e RUIZ, 2017; STURZA, 2014; entre outros), mas não podemos esquecer que o projeto de extensão que aqui será exposto nasce tanto do contexto político-linguístico apresentado, quanto pela participação do município no programa mencionado. 
Corroborando com todo o aspecto legal e social, o fator social e geográfico é de grande impacto também nas relações cotidianas e na formação da identidade regional. Foz do Iguaçu é uma das nove fronteiras tríplices do Brasil. Os três países são interligados por duas pontes: a Tancredo Neves (ou Ponte da Fraternidade) ligando Brasil e Argentina, e a Ponte da Amizade ligando Brasil e Paraguai. No momento há a construção de uma segunda ponte ligando Brasil e Paraguai. Além dos 2 rios, das 4 margens, das 2 pontes (em breve 3), há nesses países a presença de 3 línguas oficiais: espanhol, guarani e português. E claro, não podemos esquecer dos diversos migrantes que escolheram a região para habitar: chineses, coreanos, libaneses, sírios, indianos, entre diversas outras nacionalidades. Conforme dados da Polícia Federal ${ }^{1}$, a cidade possui 81 etnias registradas oficialmente. Contudo, até o momento não há um mapeamento das línguas faladas por esses migrantes. Apesar de toda essa diversidade, atualmente pouco se vê, no setor educacional, políticas ou ações específicas que contemplem isso. Em todo município, somente no ano de 2017 foi feito um levantamento para saber quantas e quais nacionalidades estavam presentes no Ensino Fundamental I (EF I). Neste documento foi constatado que havia o registro oficial de 350 crianças não-brasileiras regularmente matriculadas no EF I, entretanto ainda não há registro de quais são as línguas faladas por esses estudantes.

Um levantamento sociolinguístico se faz de fato necessário, pois o contexto fronteiriço, de grande migração, exige uma “discussão sistemática em diferentes esferas para construir novas formas de encarar e tornar visível a presença de diversas línguas na sociedade, construindo pontes para a conformação de novos saberes" (BERGER, 2017, p.67), com a finalidade de evitar disputas sobre qual ou quais línguas devem ser ensinadas na escola. Além disso, a diversidade linguístico-cultural se faz presente no cotidiano urbano, assim como no ambiente familiar (MAIA; AMATO; CARDENAS; 2016) e, portanto, refletir sobre qual gestão de língua estará presente, é, de fato, primordial.

\section{O PROJETO}

Em 2013, o projeto de extensão, Fronteira Intercultural (FI) atuava na escola municipal Adele Zanotto Scalco, escola que também recebia/ recebe $^{2}$ o PEIF. A execução do projeto em uma escola que já tinha aulas de língua espanhola deu-se justamente pelo caráter intercultural do programa.

\footnotetext{
1 Informação retirada de https://www.clickfozdoiguacu.com.br/foz-do-iguacu-passa-a-teroficialmente-81-etnias/, acesso em 05 de outubro de 2020.

${ }^{2}$ O PEIF continuou parcialmente até o ano de 2019, havendo, no referido ano, somente a presença das professoras argentinas na escola brasileira, sem a reciprocidade de ações. Em 2020 as ações não iniciaram.
}

Revista X, v. 16, n. 2, p. 568-585, 2021. 
O objetivo principal do programa é "promover a integração regional por meio da educação intercultural que garanta formação integral às crianças e aos jovens nas regiões de fronteira do Brasil com outros países" (ESCOLAS, 2020). Além disso, ressaltava sobre a importância de transformar a escola em um ambiente intercultural, como foco primordial para o alcance deste objetivo.

No documento marco do PEIF, a interculturalidade é vista como um conjunto de práticas sociais relacionadas ao conviver com o outro. Neste sentido, todo contato qualificado com uma outra cultura, com uma outra língua e com outros saberes é considerado nesse documento, uma abordagem intercultural. O entendimento de interculturalidade se dá também no compartilhamento de dimensões históricas, geográficas, literárias e artísticas do outro. A interculturalidade no programa se dá no reconhecimento da alteridade, o que implica a reflexão sobre as línguas (materna e adicional) e culturas que circulam; assim, ao tratar do outro, também há um processo de autoanálise. Isso é fundamental na fronteira, pois os sujeitos que aqui habitam circulam entre os países e são sujeitos que transpõem e ultrapassam os limites do Estado-Nação tal como está imposto. A partir desta perspectiva a sala de aula deve se tornar um espaço lúdico de descobertas das línguas e culturas que circulam na região e que fazem parte do cotidiano daquela comunidade escolar.

Guilherme e Dietz (2014), ao abordarem a multiplicidade dos conceitos relacionados à cultura - multiculturalismo, interculturalidade e transculturalidade advogam por um conceito já abordado por Walsh (2010), que é a interculturalidade crítica. A autora propõe uma alteração da estrutura social a partir de sua base, ocupada pelos sujeitos que, nas relações de poder construídas historicamente, foram subalternizados, marginalizados e tiveram sua cultura e língua de alguma forma silenciada; compreendido como um projeto decolonial, que transforma e refunda a sociedade, tal como nos traz Paulo Freire (1970) em sua obra. Guilherme e Dietz (2014) apontam que o conceito defendido por Walsh (2010) tem a potencialidade de aproximar a relação norte - sul, através da tradução de diferenças e desigualdades manifestadas nas perspectivas discrepantes sobre mundo, sujeito, moral, ou seja, os polos colonizador - colonizado.

A partir de uma perspectiva crítica e decolonial de interculturalidade, o projeto FI buscava apresentar aspectos culturais de países hispano-americanos, em língua espanhola - aqui sendo a língua adicional, para crianças do Ensino Fundamental I e último ano da Educação Infantil. Como já mencionado, o projeto teve seu início em uma escola que já tinha como pressuposto ser um ambiente intercultural. Assim, pensando uma educação para o entorno (MAHER, 2012), buscamos trazer práticas linguístico-culturais que refletissem a realidade fronteiriça local, compartilhada por saberes globais. 
Garcia (2009, p. 45) afirma que “em comunidades bilíngues, também é importante translinguajar, a fim de fazer sentido de signos escritos nas duas ou mais línguas da comunidade, que geralmente estão comunicando mensagens diferentes", e o contexto de atuação do projeto, considerado multilíngue e pluricultural, oportuniza a comunicação entre e com os idiomas, promovendo o translinguajar.

Yip e Garcia (2018, s.p.), salientam a necessidade de se ter em mente que as crianças plurilíngues ativam seu repertório semiótico constantemente, não importando qual língua estão usando e que não se deve avaliar os estudantes sem ter em mente a amplitude de seus repertórios plurais. As autoras (2018, s.p.) advogam que não basta uma postura da professora ou do professor para que as translinguagens emerjam em sala de aula, para elas

A postura dos professores, as suas crenças filosóficas sobre o valor do bilinguismo, na vida de uma criança falante de línguas minoritárias é muito importante. Exceto se o professor tenha uma postura crítica sobre as práticas de reducionismos linguísticos que ocorrem nas escolas, ele ou ela não procurará por espaços com translinguagens em suas classes. Exceto se o professor enxergue a si mesmo como um co-aprendiz, disponível para aprender com as crianças sobre as suas práticas linguísticas e culturais, além de suas compreensões de mundo, não será possível criar um espaço para as translinguagens. Por isso é necessário muito mais do que simplesmente uma postura, uma vez que as translinguagens são sempre estratégicas e propositais.

Nesse sentido, o trabalho com e a partir de imagens foi de crucial importância para refletir sobre estereótipos e preconceitos e trazer à tona as translinguagens da comunidade em questão.

\section{O TRABALHO}

O projeto FI foi criado com o foco em uma abordagem intercultural, a partir de uma perspectiva decolonial. O objetivo do projeto era aproximar culturas latino-americanas da realidade social vivenciada pelas crianças da escola participante do PEIF. As atividades eram ministradas em língua espanhola, com estudantes bolsistas nascidas em países hispano-americanos. Muitas das bolsistas participantes tinham pouca proficiência/ fluência na língua portuguesa, o que tornava a aprendizagem mútua e colaborativa entre crianças e bolsistas.

A perspectiva decolonial que trazíamos, era vista como um exercício para a liberdade e de construção da alteridade, pois conforme Freire (1977, p.78), ensinar Revista X, v. 16, n. 2, p. 568-585, 2021. 
“(...) não é transferência ou transmissão do saber nem da cultura; não é a extensão de conhecimentos técnicos (...); não é a perpetuação de valores de uma cultura dada (...)", mas sim um fazer dialógico, pois para esse autor (op.cit., p. 43)

Ser dialógico é não invadir, é não manipular, é não sloganizar. Ser dialógico é empenhar-se na transformação constante da realidade. Esta é a razão pela qual, sendo diálogo o conteúdo da forma de ser própria à existência humana, está excluído de toda relação na qual alguns homens sejam transformados em 'seres para o outro' por homens que são falsos 'seres para si'. É que o diálogo não pode travar-se numa relação antagônica.

Os aspectos culturais abordados nas aulas eram especificamente de países latinoamericanos e caribenhos, sendo alguns deles trazidos a partir da epistemologia e visão de povos originários. Contudo, apesar de, a princípio parecer um conteúdo distante, sempre buscávamos relacionar com a vivência e experiência das próprias crianças, aproximando as culturas diversas e refletindo sobre si e sobre o outro, a partir das línguas e das representações feitas.

O trabalho expandiu-se para outras escolas que não acolhiam um programa específico com destaque para a interculturalidade. Apesar disso, o histórico contextual de Foz do Iguaçu revela que as escolas refletem o ambiente multicultural e multilíngue da cidade. Porém, nota-se que não há um planejamento que contemple toda a diversidade linguístico-cultural da comunidade escolar, conforme observado em pesquisa realizada sobre os Projetos Políticos Pedagógicos (PPPs) das escolas (AMATO; ARVELOS, 2019; LIMA, 2019). Foz do Iguaçu tem como base um currículo regional, elaborado pela Associação dos Municípios do Oeste do Paraná (AMOP). Ao analisarmos esse documento, podemos observar que há uma informação sobre a constituição histórica social da região. Contudo, a questão da territorialidade, na qual a diversidade linguísticacultural está presente devido a forte migração e as fronteiras entre dois países, não é citada em nenhum momento. Assim, apesar do contexto regional fortemente marcado pela migração nacional e internacional e da ciência de que estamos em território indígena, os países e povos vizinhos não são citados no documento que guia a formulação dos PPPs de Foz do Iguaçu. Assim sendo, as escolas não incluem essa diversidade em seus documentos. Em análise detalhada dos PPPs, observamos que o termo interculturalidade só aparece quando há menção sobre as leis específicas que tratam do ensino da cultura afro-brasileira e indígena. Desta forma, há a exclusão de uma parte da população que participa da escola e, também do contexto social no qual esses sujeitos habitam. 
Nesse sentido, o projeto FI se adequa em qualquer contexto escolar, mantendo os mesmos objetivos, pois busca promover uma educação intercultural através da cultura latino-americana e caribenha. Nos diferentes anos de funcionamento, o planejamento era um foco de formação e elaboração de conteúdo. Havia a escolha de um tema específico, sempre em conjunto com a estudante bolsista participante. Foram trabalhados distintos assuntos, tais como lendas e personagens folclóricos, patrimônio material e imaterial, recontos.

\section{DESCRIÇÃO DAS AÇÕES}

As atividades tinham duração de trinta minutos e eram realizadas durante o período escolar, ou seja, no turno regular. Foram ministradas ações em turmas do último ano da Educação Infantil até o último ano do EF I. Com idades tão diversas, o planejamento também foi individualizado, adaptado a cada etapa, havendo um bloco de ações para crianças até o $2^{\circ}$ ano do EF I e outro para as crianças já alfabetizadas (do $3^{\circ}$ ao $5^{\circ}$ ano). Cada tema era abordado em média durante quatro encontros: no primeiro havia a contextualização, no segundo a apresentação, no terceiro a fixação e no quarto a recontextualização. As imagens que traremos a seguir estão vinculadas a última etapa, pois essa é vista para nós como autoral, trazendo os desejos das crianças participantes e suas vozes, e, também tinha a proposição de ser a parte prática da atividade, na qual as crianças pudessem trazer e refletir sobre seu contexto.

\section{Figura 1}

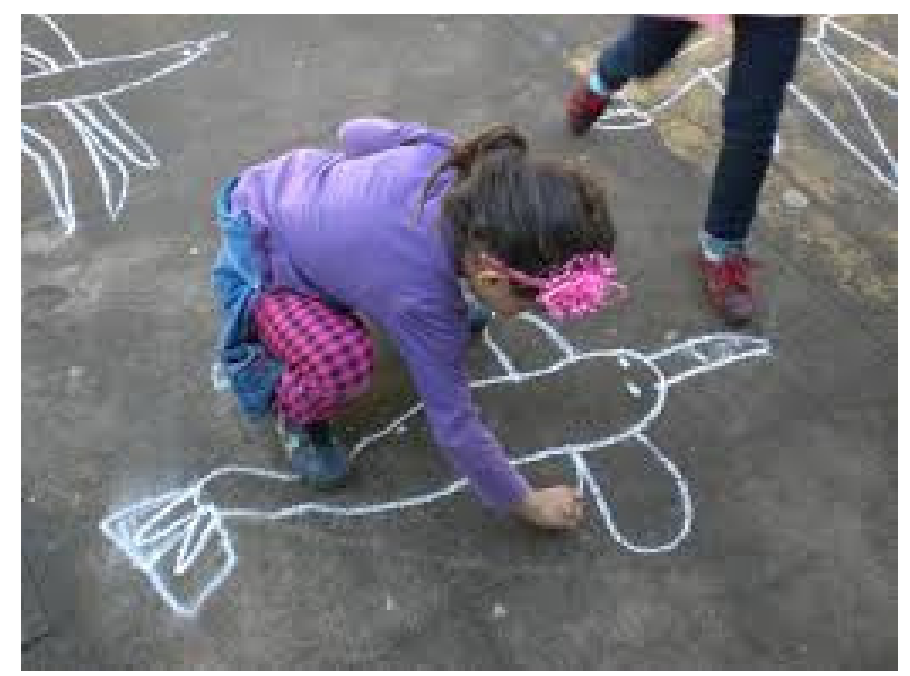

Fonte: autoria própria. 
\#PraCegoVer: Fotografia colorida. A imagem focaliza uma menina de 7/8 anos desenhando com giz branco um beijaflor num piso cinza. A menina usa uma tiara rosa na cabeça, uma blusa roxa de manga comprida, uma calça xadrez rosa e preta, uma jaqueta jeans amarrada na cintura e um tênis preto.

Na figura 1 podemos observar o desenho de um beija-flor feito por uma criança do $2^{\circ}$ ano do EF I. Essa imagem foi feita após a apresentação das linhas de Nazca, no Peru. Como parte autoral, as crianças deveriam ir ao pátio da escola e desenhar com giz o animal que mais viam perto de suas casas. Foram desenhados cachorros, gatos, pássaros, cavalos e com isso as crianças aproximaram-se de uma cultura muito antiga do continente e pouco vista nas escolas ou no conteúdo de livros didáticos. Pudemos atentar que a troca linguística foi intensa, pois o tema versava sobre animais - algo que crianças adoram - e muitas palavras desconhecidas (pela bolsista e pelas crianças) foram trazidas à tona e o aprendizado foi profícuo.

Figura 2

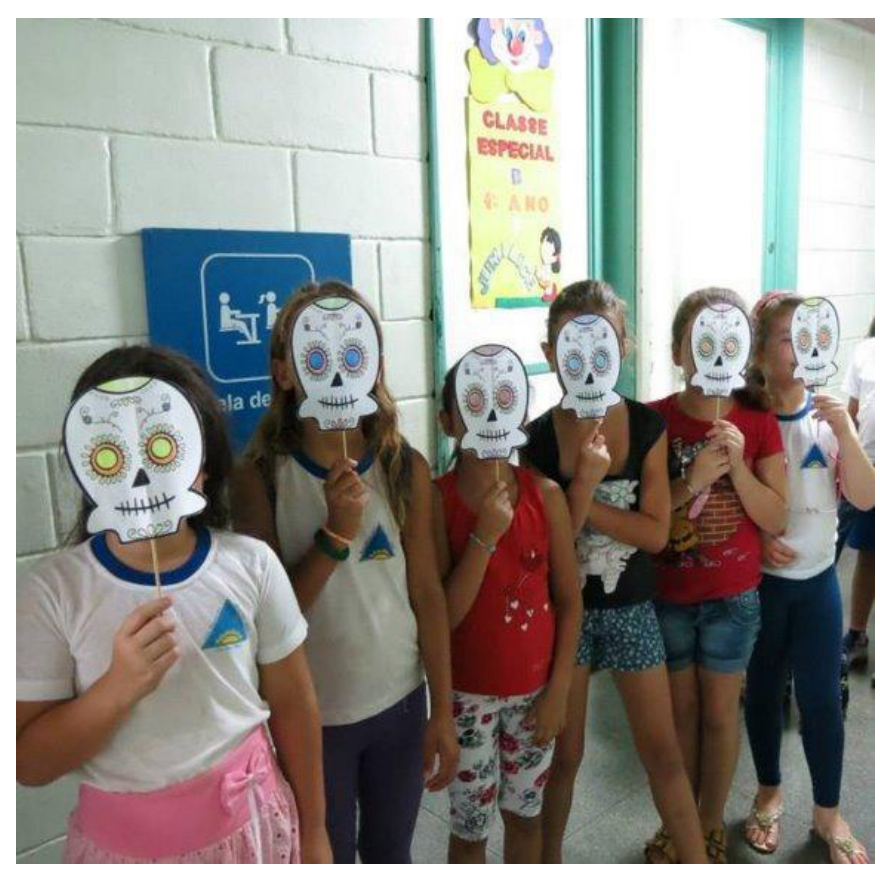

Fonte: autoria própria.

\#PraCegoVer: Fotografia colorida. Seis crianças entre 9-10 anos, algumas usam uniforme e outras com camisetas, calções e saia. Cada uma segura uma máscara de caveira colorida em frente aos seus rostos. Todas estão de frente para a câmera. A caveira colorida lembra o Dia de los Muertos. 
Já na figura 2 vemos a representação do Dia de los Muertos, comemoração tradicional mexicana. As crianças do $4^{\circ}$ ano, após tomarem conhecimento sobre a data, escolherem apresentar uma dança coreografada por elas, com máscaras pintadas por elas e moldes feitos pela bolsista ministrante. Em comum acordo, com direção e professora regente, as crianças escolheram, ensaiaram e apresentaram a música para toda a escola, em uma atividade cultural envolvendo toda a comunidade escolar.

As figuras de 3 a 7 estão vinculadas ao tema do reconto. Esse tema foi trabalhado durante dois anos seguidos, com todos os anos já especificados (último ano da Educação Infantil e EF I), a pedido das escolas participantes. Os recontos foram aplicados a partir de uma coleção da editora argentina Albatroz, cujo livros trazem os contos de fadas tradicionais do hemisfério norte, tais como Chapeuzinho Vermelho, Branca de Neve, Pequena Sereia, entre outros, ambientados em regiões da Argentina e protagonizados por comunidades autóctones. Um exemplo disso é a Chapeuzinho Vermelho que se encontra na região noroeste da Argentina, local de forte presença quéchua, com a população apresentando traços indígenas, com vestimenta colorida e paisagem geográfica desértica. Assim, escolhíamos histórias com um enredo bem conhecido pelas crianças, apresentávamos a comunidade e o local onde o reconto era ambientado e ao apresentarmos a história, sempre contada em língua espanhola, não observávamos nas crianças algum tipo de estranhamento com o fato da chapeuzinho vermelho da história contada não ter a pele branca ou não passear por bosques de árvores altas e não levar doces para vovó, mas tamales. As palavras que poderiam gerar dúvidas, por serem falso cognatos ou por serem muito distantes do português, eram representadas por pictogramas e durante a contação eram mostrados para elas e assim as crianças visualizavam a representação do conceito, compreendendo, por exemplo o que eram "tamales", do seu modo e trazendo o significado para seu próprio contexto. As figuras 3 e 4 traduzem a ressignificação da história, com as características de uma "Chapeuzinho" na qual as próprias crianças se reconheceram e vagando por caminhos conhecido por elas. Assim, vemos na figura 4 a personagem passeando pelas ruas da cidade e transitando próximo a um grande hotel localizado na região central, cerca de $9 \mathrm{~km}$ distante da escola. Além disso, ao invés de levar doces, a personagem regional levava sopa paraguaia ${ }^{3}$ para a vovó, conforme relato oral das crianças e disposto na figura 3.

\footnotetext{
${ }^{3}$ Torta salgada de milho e queijo, típica do Paraguai. Iguaria muito consumida em Foz do Iguaçu e facilmente encontrada em supermercados. 


\section{Figura 3}

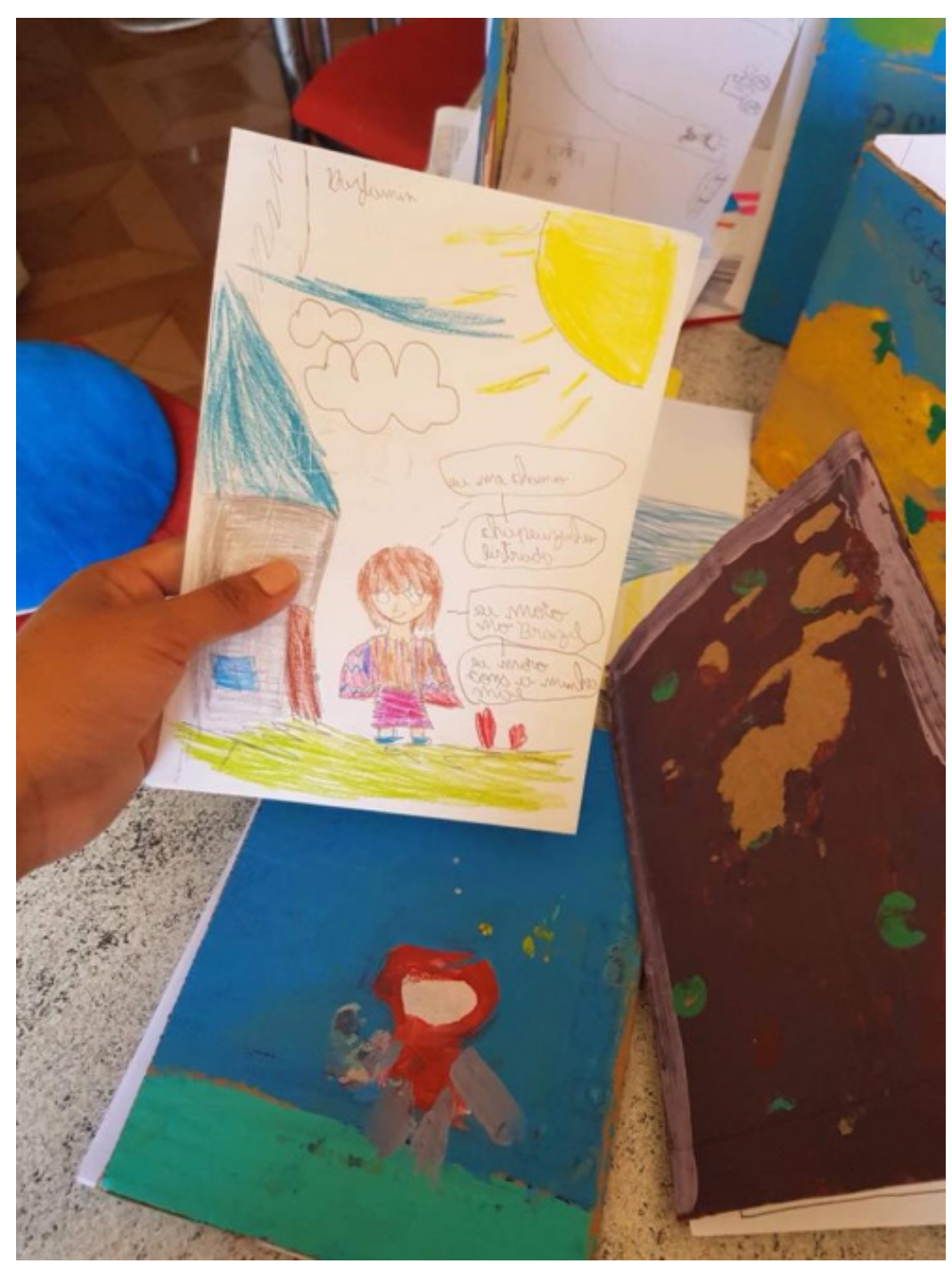

Fonte: autoria própria.

\#PraCegoVer: Fotografia colorida. Vários desenhos coloridos estão dispostos na imagem. Em primeiro plano alguém segura um dos desenhos onde aparece da esquerda para direita, uma casa, uma criança, vários balões de fala, o sol brilhando forte no canto superior direito e algumas nuvens pelo céu. 


\section{Figura 4}

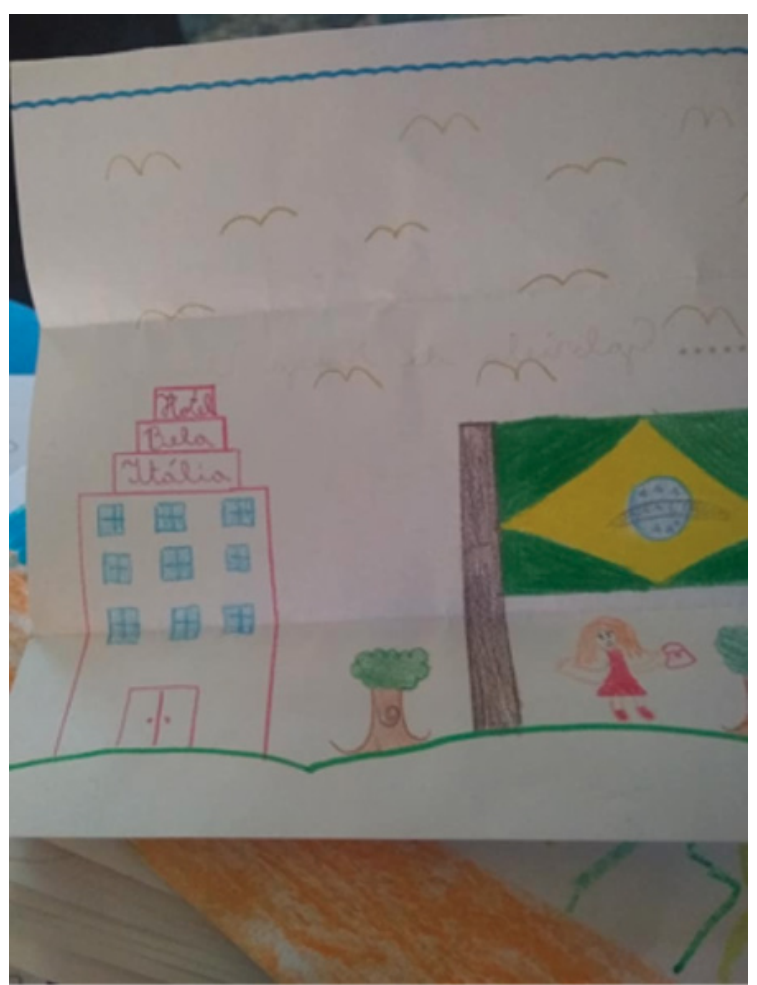

Fonte: autoria própria.

\#PraCegoVer: Fotografia de um desenho colorido. Lado esquerdo um prédio, no alto uma placa com as informações: Hotel Bela Itália. Lado direito uma enorme bandeira do Brasil, embaixo da bandeira uma menina e bem no centro da folha, uma árvore. No céu algumas gaivotas.

A figura 5 é resultado do reconto sobre a Branca de Neve. Nesta representação as crianças trouxeram elementos da história original e do reconto, como o espelho, mas também desenharam figuras do reconto, como o alimento que a personagem principal comeu e ficou desacordada e elementos da natureza, como a cachoeira. Nota-se que as crianças optaram por trazer os elementos da história para dentro do espelho, como se ele refletisse as partes que elas consideraram como sendo mais importantes de todo o conteúdo narrado. As cores usadas na moldura do espelho estão constantemente presente no reconto, e a comunidade indígena yagan é a representada nesse conto. Cabe informar que até o momento há somente uma falante viva do idioma yagan e essa é a comunidade indígena mais meridional que se tem registro, sendo dificilmente mencionada em livros ou materiais didáticos brasileiros, portanto caso não fosse essa atividade, muito provável que as crianças jamais tivessem contato, em ambiente escolar, sobre essa população. 


\section{Figura 5}

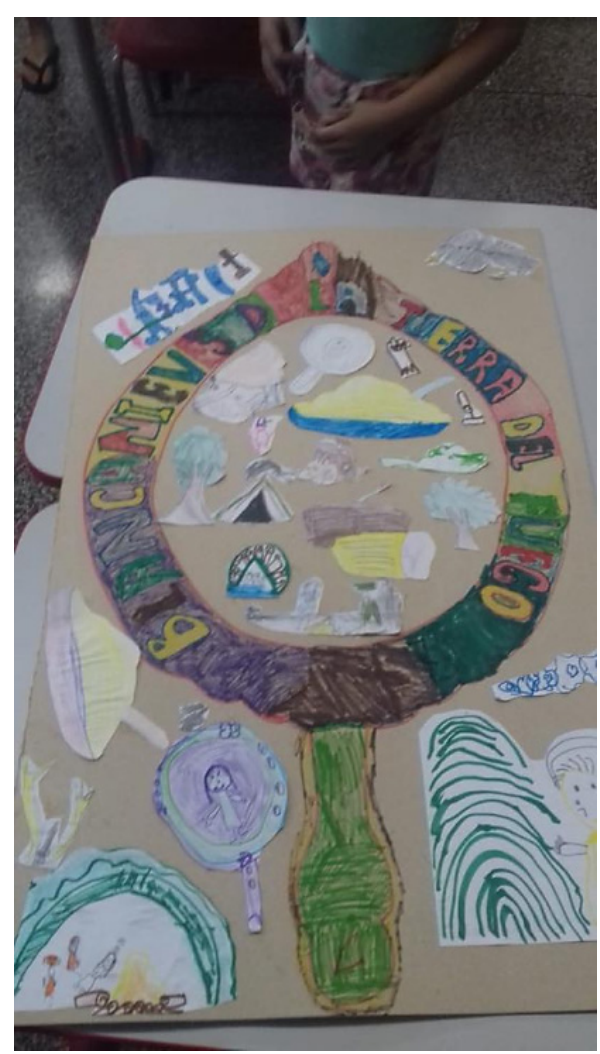

Fonte: autoria própria.

\#PraCegoVer: Fotografia de um cartaz. Desenho e colagem coloridos. O desenho do espelho da branca de neve ocupa quase todo o espaço do cartaz. O cabo do espelho é verde e sua moldura está bem colorida, dentro da moldura a escrita: Blanca de Nieve de la tierra del fuego. No centro e em volta do espelho há vários desenhos colados: árvores, cabanas, espelhos pequenos, pratos de comidas, animais, lenhador.

A última etapa da atividade, isto é, a recriação, também era uma oportunidade em apresentar formas diversas do trabalho artístico. Na figura 6, por exemplo, vemos uma maquete que representou a história da Cinderela que se passou durante o Império Maia. O trabalho da figura 6 foi realizado por uma turma do $3^{\circ}$ ano e o destaque encontra-se na arquitetura e na selva. As crianças escolheram o que mais as impactaram na história e a arquitetura maia, com as pirâmides foi algo bem representativo. Elas comentaram que não sabiam que existiam pirâmides na América Latina. Para elas, as pirâmides só estavam no Egito. Isso nos surpreendeu, pois as crianças ainda não tinham aprendido na escola sobre o Egito antigo. Portanto, elas só tiveram acesso a esse conhecimento através da mídia e de outros ambientes não escolares e isso nos mostra como a cultura de outros países do continente não é vista e tão divulgada quanto culturas mais distantes. 


\section{Figura 6}

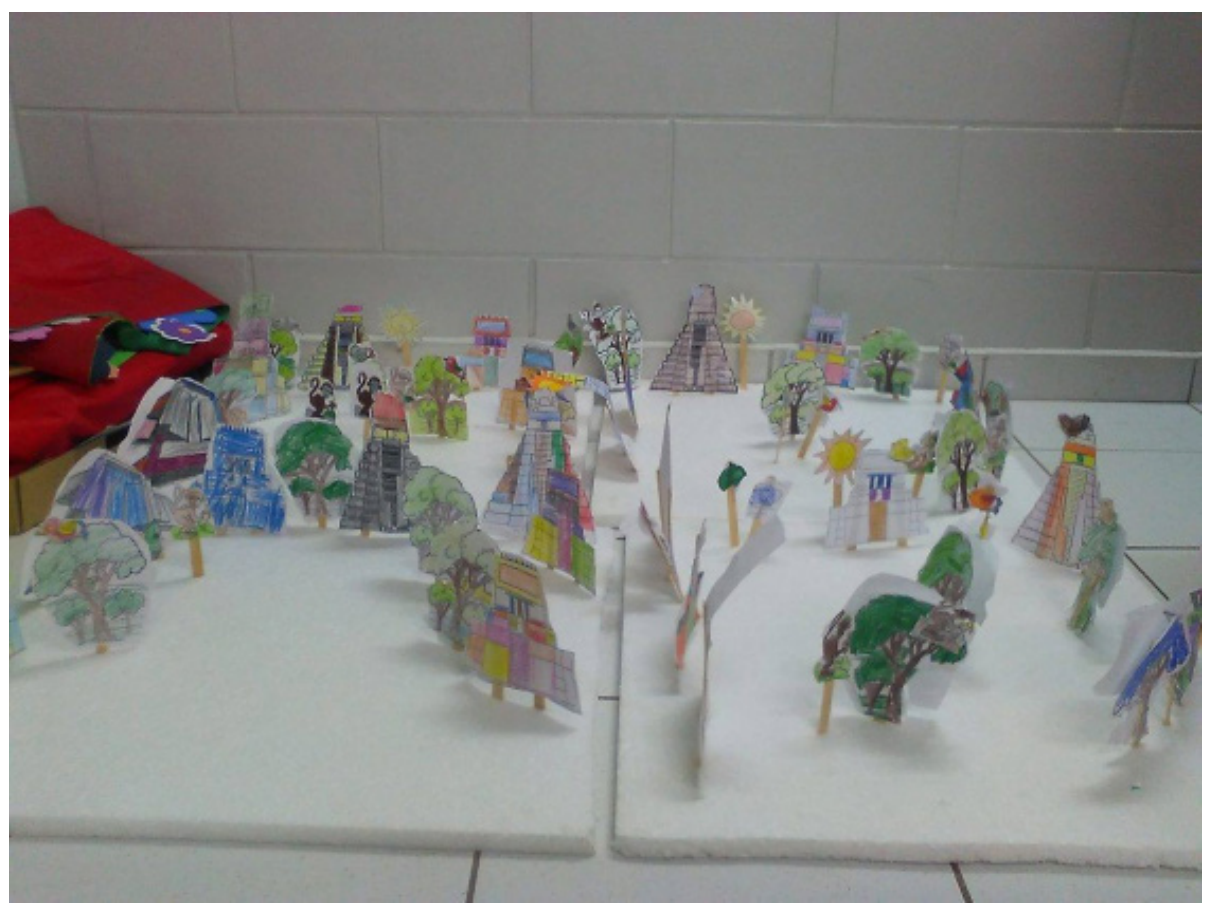

Fonte: autoria própria.

\#PraCegoVer: Fotografia de duas maquetes. Sobre placas de isopor estão fixados vários desenhos coloridos. Cada desenho possui um palito que o deixa fixo no isopor. Entre os desenhos estão: árvores de vários formatos e tamanhos, pirâmides, pessoas com roupas coloridas, símbolos e construções maias.

Aqui na figura 7 há algo de muito representativo na fronteira, como podemos observar a partir da representação da bandeira argentina. Esse desenho foi feito após a contação da história sobre a Pequena Sereia, que se passava na Patagônia, evidenciando a comunidade tehuelches. Podemos observar na figura 7 que a sereia está em um rio conhecido pelas crianças, tendo em vista que a fronteira do Brasil com a Argentina é cortada por um grande rio e este é muito presente no cotidiano da cidade. Este desenho chama atenção tanto pela sereia desenhada, quanto pela bandeira ilustrada. Nota-se que a sereia possui pele branca e cabelos loiros; apesar do foco da história na população indígena, o forte imaginário inculcado nas mentes infantis da princesa com características europeias ainda é muito difícil de ser transformado e mesmo apresentando outras formas e outras figuras, o imaginário popular ainda vem à tona, evidenciando a necessidade de desconstruirmos essas imagens fixas e apresentando figuras nas quais as crianças se identifiquem. Outro ponto de destaque é a bandeira argentina, como já mencionado. Ao mesmo tempo em que a representação da personagem principal se manteve nos moldes 
tido como padrão, as fronteiras físicas foram transpostas e a Pequena Sereia está em solo argentino, assim, podemos observar a importância em valorizar e apresentar outras culturas para as crianças. E nesse caso, a língua e cultura apresentadas estão próximas às crianças e presentes no cotidiano delas.

\section{Figura 7}

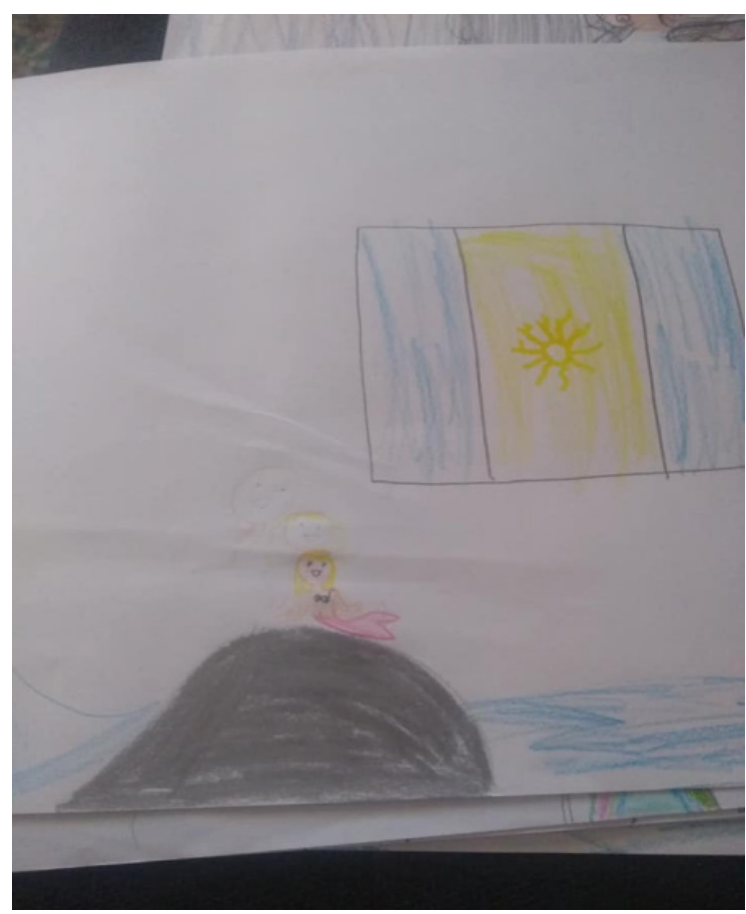

Fonte: autoria própria.

\#PraCegoVer: Desenho colorido. No centro uma enorme pedra escura e sobre ela uma sereia, ela tem a cauda rosa, pele clara e cabelos loiros e compridos. Em volta da pedra apenas água. Acima, no canto superior direito a bandeira da Argentina.

\section{BREVES CONSIDERAÇÕES}

Língua e cultura são consideradas indissociáveis. Em contexto de fronteira, a circulação das línguas e das culturas é constante e permanente. Enquanto sujeitos transfronteiriços, que circulam e constituem a região, os sujeitos escolares, sociohistoricamente constituídos, reelaboram incessantemente o viver e conviver na fronteira. Segundo Yip e Garcia (2018, s.p.), 
Todos podem aprender com uma abordagem pelas translinguagens, desde que sejam niveladas as regras do jogo e colocados os alunos com diferentes perfis em contato uns com os outros. As translinguagens podem ajudar a desenvolver uma consciência linguística crítica que é necessária para todas as comunidades de hoje.

Mas não podemos romantizar o convívio entre as línguas, pois há uma disputa de saberes e um mercado linguístico (BOURDIEU, 1996) envolvido, cujo poder simbólico e de circulação das línguas está fortemente marcado. As posições dos sujeitos e as decisões por eles tomadas induzem a uma maior ou menor abertura em relação ao outro; as lutas simbólicas podem manter ou remodelar posições discursivas nos mais diferentes âmbitos e espaços. Programas como o PEIF tem como princípio a disrupção de uma ordem discursiva, da qual os sujeitos estão impregnados e tomando em conta uma abordagem intercultural que busque a emancipação dos sujeitos a partir das línguas materna e adicional(is). Desta forma, novos enunciados passam a ser legitimados e circulam com efeito de verdade e assim transformam-se em ação. Conforme Hall (1999, pág. 13), “à medida em que os sistemas de significação e representação cultural se multiplicam, somos confrontados por uma multiplicidade desconcertante e cambiante de identidades possíveis, com cada uma das quais poderíamos nos identificar - ao menos temporariamente", assim, o contato intercultural é um constante deslocar-se e reordenar-se. Contudo, não podemos esquecer que essa multiplicidade abordada por Hall (1999) é cotidiana em contexto de fronteira. Cabe ao contexto escolar, portanto realizar encontros e confrontos sistematizados e coordenados. Pois como afirmam Maia, Amato e Cardenas (2016, p.50)

Assim, ao trabalhar com a diversidade linguístico-cultural presente na escola hoje, promovendo uma troca efetiva entre os saberes e culturas proporcionados pelas línguas em circulação na comunidade escolar, poderemos também promover atitudes crítico-reflexivas sobre o próprio e o Outro, estabelecendo assim formas de aproximação e respeito para com o diferente e aprendendo a respeitar e a valorizar a própria identidade, para nos tornarmos pelo menos e verdadeiramente bilíngues.

Neste contexto, trabalhar com e a partir de imagens auxilia na compreensão de si e do Outro através da reflexão semiótica proporcionada pelas representações primárias (desenhos/ imagens mostradas) e secundárias (desenhos/imagens/ textos/ pinturas reproduzidas), ideia corroborada por Simões (2017, p. 89), “o desenho permite ao sujeito projetar-se no irreal, no virtual e imaginário sem ser julgado, ao mesmo tempo em que 
pode representar o universo de referência e de perceção [sic] das relações sociais dos indivíduos, mais ou menos estereotipado."

Com isso observamos que a dinâmica de trabalho com produções visuais em uma abordagem intercultural auxilia na elaboração e no reconhecimento das culturas locais, regionais e globais, em um mesmo espaço, como um caldeirão de diversidade que borbulha o ser/estar com o Outro e pelo Outro; e a escola torna-se esse espaço fundamental para consolidar essa reflexão e esse caldeirão de multiplicidade linguístico-cultural presente na fronteira e vivenciada cotidianamente pelos seus habitantes.

\section{AGRADECIMENTOS}

Agradeço ao financiamento da Pró-reitoria de Extensão e ao apoio da Secretaria Municipal de Educação de Foz do Iguaçu (SMED - Foz).

\section{REFERÊNCIAS}

ALVES DE SOUSA, F.; ALBUQUERQUE, J. L. C.. Nação e integração nas escolas de fronteira: a mobilidade docente e a aprendizagem das línguas nacionais entre o Brasil e a Argentina. Etnográfica, Lisboa, v. 23, n. 3, p. 627-648, out. 2019. Disponível em $<$ http:// www.scielo.mec.pt/scielo.php?script $=$ sci_arttext\&pid=S0873-65612019000300005\&ln $\mathrm{g}=\mathrm{pt \& nrm}=\mathrm{iso}>$. Acesso em 23 set. 2020.

AMATO, L. J. D.; RUIZ, A. Y., "Patrimônio, língua e interculturalidade na escola pública: práticas e saberes”, Interletras, 6 (25): 1-12, 2017.

AMATO, L. J. D.; ARVELOS, R. M. A FRONTEIRA NA ESCOLA: imaginários e narrativas escolares em Foz do Iguaçu. Revista Eletrônica Científica Ensino Interdisciplinar, v. 5, p. 431-442, 2019.

MAIA, F. P. S.; AMATO, L. J. D.; CARDENAS, L. O. Relações Bilingues em escola pública no Programa Escolas Interculturais de Fronteira (PEIF). In: Rubens Lacerda de Sá. (Org.). Português Para Falantes de Outras Linguas: Interculturalidade, Inclusão Social e Políticas Linguísticas. 1ed.Campinas: Pontes, 2016, v., p. 33-54.

BERGER, I. R. Gestão da diversidade linguística na educação formal no Brasil: desafios para uma política linguística. (CON)TEXTOS LINGUÍSTICOS, v. 11, p. 54-69, 2017.

BOURDIEU, P. A economia das trocas lingüísticas. São Paulo: Editora da USP, 1996. 
ESCOLAS de Fronteiras. Educação Integral. Disponível em: http://educacaointegral. mec.gov.br/escolas-de-fronteira. Acesso em 23 de setembro de 2020.

FREIRE, P. Extensão ou comunicação? 3. ed. Rio de Janeiro: Paz e Terra, 1977. Pedagogia do Oprimido. Rio de Janeiro: Paz e Terra, 1970.

GARCIA, O. Bilingual education in the 21st century: a global perspective. [S.1.]: WileyBlackwell, 2009.

GUILHERME, M. \& DIETZ, G. Diferencia en la diversidad: Perspectivas múltiples de complejidades conceptuales multi, inter y trans-culturales (submitted to Estudios sobre Culturas Contemporáneas), 20:40, 13-36, 2014.

HALL, S. A identidade cultural na pós-modernidade. São Paulo: D\&P, 1999.

LIMA, Bárbara Ferreira de. Educação Escolar na Tríplice Fronteira: crianças falantes de espanhol nas escolas municipais de Foz do Iguaçu. 2019. 52 p. Trabalho de Conclusão de Curso (Graduação em História - América Latina) - Universidade Federal da Integração Latino-Americana, Foz do Iguaçu, 2019.

MAHER, T. M. A Educação do Entorno para a Interculturalidade e o Plurilinguismo. In: KLEIMAN, A.B., CAVAlCANTI, M. C. (orgs.) Lingüística Aplicada - suas Faces e Interfaces. Campinas, SP: Mercado de Letras, 2007, p.255-270.

TONELLI, J. R. A.; CHAGURI, J. de P. Ensino de Língua Estrangeira para Crianças: O ensino e a Formação em Foco. Curitiba: Appris, 2013. 2 ed.

RIBEIRO, S. B. C. Acolhimento intercultural e ensino de português como língua adicional nas escolas municipais de Foz do Iguaçu.DOMÍNIOS DE LINGU@GEM, v. 12, p. 940973, 2018.

SIMÕES, A. R., Vamos desenhar línguas e a sua aprendizagem? - o desenho como forma de aceder a representações de adolescentes. In: Melo-Pfeifer \& Simões, (ed.). Plurilinguismo vivido, plurilinguismo desenhado: estudos sobre a relação dos sujeitos com as línguas, 2017. E-Book. Disponível em: https://www.researchgate.net/publication/321221118_ Melo-Pfeifer_Simoes_2017_ed_Plurilinguismo_vivido_plurilinguismo_desenhado_ estudos_sobre_a_relacao_dos_sujeitos_com_as_linguas_E-Book. Acesso em 10 de outubro de 2020.

STURZA, Eliana Rosa. Das experiências e dos aprendizados no Programa Escolas Interculturais de Fronteiras. In: Salto para o Futuro - Escolas Interculturais de Fronteira Ano XXIV, Boletim 1, maio de 2014. 
WALSH, C. Interculturalidad crítica y educación intercultural. In: J. Viaña, L. Tapia \& C. Walsh (Eds.). Construyendo Interculturalidad Crítica. La Paz: Instituto Internacional de Integración, pp. 75-96, 2010.

YIP, J., GARCÍA, O. Translinguagens: recomendações para educadores. Iberoamérica Social: revista-red de estudios sociales IX, pp. 164 - 177, 2018. Recuperado en https:// iberoamericasocial.com/translinguagens-recomendacoes-educadores

Recebido em: 12 out. 2020. Aceito em: 07 dez. 2020. 